\title{
Sodium salicylate reduced mRNA abundance of hypoxia-associated genes in MAC-T cells
}

\author{
C. M. Ylioja, ${ }^{1} \odot$ T. H. Swartz, ${ }^{1,2} \odot$ L. K. Mamedova, ${ }^{1,2} \odot$ and B. J. Bradford ${ }^{1,2 *} \odot$
}

\section{Graphical Abstract}

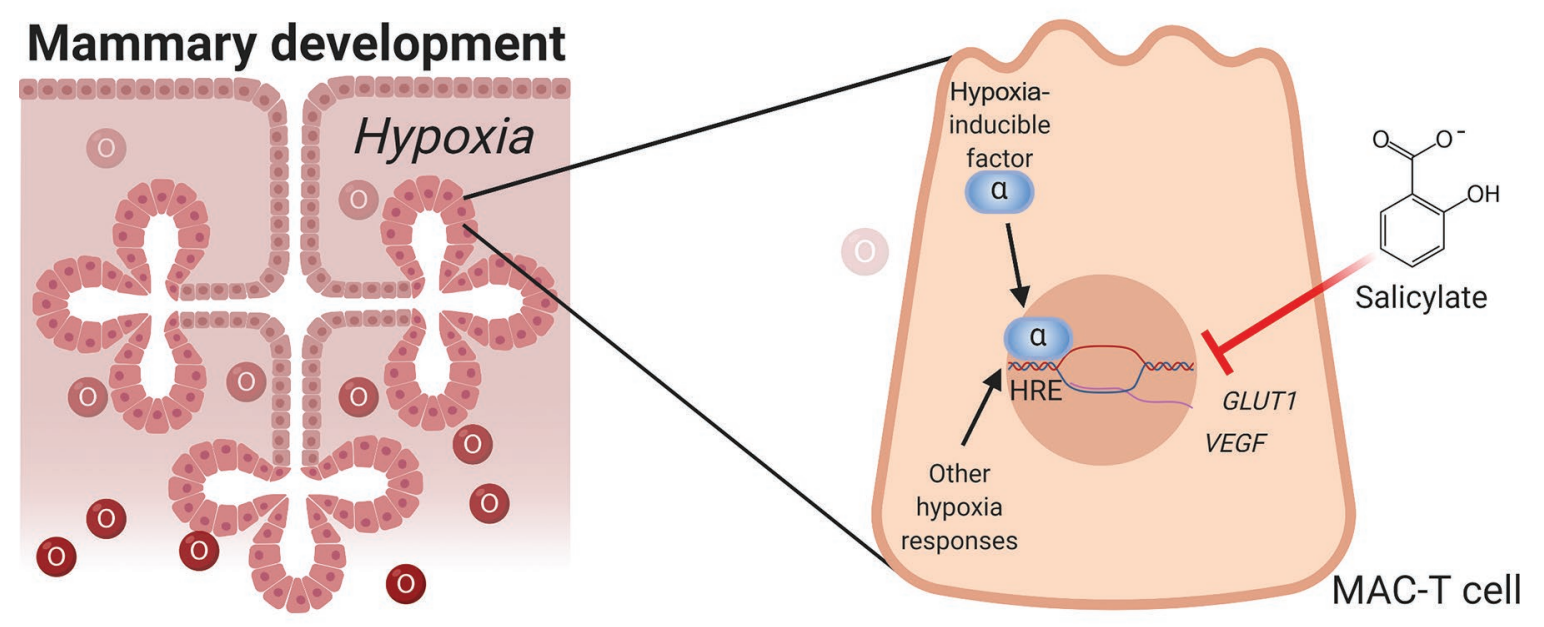

\section{Summary}

It is likely that transient hypoxia occurs with rapid development of the mammary gland during lactogenesis. Overlapping transcriptional responses to inflammatory stimuli and hypoxia point to potential interactions in regulation of tissue development. In the MAC-T mammary epithelial cell line, hypoxia induced expression of glucose transporter 1 (GLUT1), whereas the anti-inflammatory drug sodium salicylate decreased mRNA abundance of GLUT1 and heterogeneous nuclear ribonucleoprotein D and tended to suppress expression of the paracrine vascular growth factor vascular endothelial growth factor A. Although interactions of hypoxia and salicylate were only detected for GLUT1 abundance, salicylate treatment generally opposed previously reported transcriptional responses to hypoxia.

\section{Highlights}

- Sodium salicylate decreased abundance of transcripts involved in mammary development.

- Knockdown of HIF-1a did not prevent hypoxia-induced glucose transporter 1 expression.

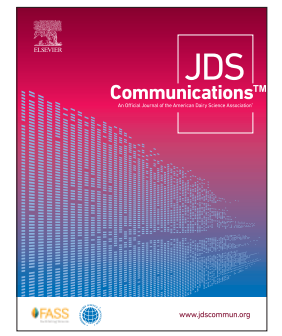

- Few interactions between hypoxia and sodium salicylate were observed. 


\title{
Sodium salicylate reduced mRNA abundance of hypoxia-associated genes in MAC-T cells
}

\author{
C. M. Ylioja, ${ }^{1} \odot$ T. H. Swartz, ${ }^{1,2} \odot$ L. K. Mamedova, ${ }^{1,2} \odot$ and B. J. Bradford ${ }^{1,2 *} \odot$
}

\begin{abstract}
Hypoxia is an oxygen deficiency commonly found in growing tissues and is speculated to occur in the rapidly developing mammary gland in peripartum dairy cattle. Low oxygen concentrations can activate hypoxia-inducible factor-1 (HIF-1), which increases transcription of genes involved in angiogenesis (VEGFA) and glucose transport (GLUT1), among other processes. The mRNA stability of these genes is positively regulated by heterogeneous nuclear ribonucleoprotein D (HNRNPD; also known as AUF1). In our previous research, postpartum administration of sodium salicylate (SS) increased whole-lactation milk yield in multiparous cows but tended to reduce milk yield in primiparous cows. Because rapid mammary tissue development likely occurs in cows approaching first lactation, we hypothesized that SS inhibited the activation of HIF-1 $\alpha$ and decreased transcription of downstream targets. MAC-T cells were treated with SS $(100 \mu M)$ or control medium before incubation under either hypoxic $\left(1 \% \mathrm{O}_{2}\right)$ or normoxic conditions for $12 \mathrm{~h}$. Additionally, cells were transfected with either HIF1A small interfering RNA (siRNA) or a scrambled siRNA negative control $48 \mathrm{~h}$ before hypoxia treatments. HIF1A, GLUT1, VEGFA, and HNRNPD were quantified relative to the internal control gene NENF. Transcript abundance was assessed using a linear mixed model with the fixed effects of SS, hypoxia, siRNA, and all 2- and 3-way interaction terms and the random effect of plate nested within hypoxia. Treatment with SS interacted with hypoxia for GLUT1, as SS reduced GLUT1 when MAC-T cells were cultured in normoxic conditions; however, no effect of SS was found in hypoxia-treated cells. Regardless of oxygen status, SS reduced HNRNPD and tended to decrease VEGFA mRNA relative to untreated cells. Hypoxia increased GLUT1, yet no effect was observed on VEGFA or HNRNPD. Small interfering RNA knocked down HIF1A, but no effect was found on GLUT1, VEGFA, or $H N R N P D$. In conclusion, SS reduced transcript abundance of genes involved with mammary gland development but generally did not interact with oxygen status.
\end{abstract}

D uring late pregnancy, the mammary epithelium must rapidly expand to support lactation. Endocrine control on bovine mammary gland development has been extensively studied (Tucker, 2000); however, little is known about the effect of oxygen availability. Hypoxia is an oxygen deficiency commonly found in growing tissues and is speculated to occur in the mammary gland (Shao and Zhao, 2014). An increase in oxygen consumption was noted in the mammary gland of goats during late pregnancy and into lactation (Reynolds, 1967; Davis et al., 1979). During lactogenesis, oxygen demands of growing mammary tissue may outpace vascular growth and blood supply, potentially causing a transient local hypoxic environment. Low oxygen concentrations can activate hypoxia-inducible factor-1 (HIF-1). This transcription factor has 2 subunits, HIF- $1 \alpha$ and HIF- $1 \beta$, with the former being stabilized during hypoxic conditions and its expression highly regulated and the latter being constitutively expressed (Semenza, 2003). Activation of HIF-1 increases transcription of genes involved in angiogenesis, glucose transport, and cell survival and proliferation (Semenza, 2003). In mouse studies, mammary HIF-1 $\alpha$ demonstrated an essential role in mammary gland development (Shao and Zhao, 2014), as knockout resulted in smaller alveoli and impaired epithelial cell differentiation, which consequently resulted in a dramatic reduction in milk synthesis (Seagroves et al., 2003).

The effect of hypoxia on milk synthesis may be partly explained by its effect on glucose transporters and angiogenesis. Indeed, hypoxia increased mRNA abundance of glucose transporter 1
(GLUT1) in mouse mammary epithelial cells (Seagroves et al., 2003). Likewise, MAC-T cells cultured under hypoxic conditions had a greater mRNA abundance of GLUT1 compared with cells treated with normoxia (Shao et al., 2014). Moreover, GLUT1 transcript abundance is greater during early to peak lactation compared with either nonlactation or late lactation in multiparous cows (Komatsu et al., 2005; Finucane et al., 2008; Mattmiller et al., 2011). Lactose synthesis, which requires glucose uptake, dictates milk volume (Zhao, 2014), and thus a hypoxia-induced increase in GLUT1 may be a mechanism to augment milk synthesis. Hypoxia also plays a critical role in angiogenesis by increasing transcription of vascular endothelial growth factor (VEGF), a paracrine function to increase delivery of oxygen and nutrients to growing tissues (Forsythe et al., 1996). Thus, hypoxia-induced effects, along with shifts in hormone levels around the time of parturition, are likely important driving factors for mammary gland development.

One potential mechanism behind the downstream transcriptional effects of hypoxia-associated genes is the recruitment of heterogeneous nuclear ribonucleoprotein D (HNRNPD); HNRNPD destabilizes mRNA of DNA methyltransferase 1 (DNMT1), an enzyme that catalyzes the addition of methyl groups to DNA. Destabilization of DNMT1 mRNA causes global DNA hypomethylation (Torrisani et al., 2007; Hsiao et al., 2015), which effectively increases expression of the aforementioned hypoxia-associated genes $(\mathrm{Wu}$ et al., 2019). Moreover, in a cancer cell line, HNRNPD positively regulated VEGF and HIF-1 $\alpha$ by directly binding and stabilizing

\footnotetext{
${ }^{1}$ Department of Animal Sciences and Industry, Kansas State University, Manhattan 66506, ${ }^{2}$ Department of Animal Science, Michigan State University, East

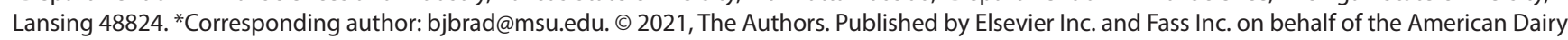
Science Association ${ }^{\oplus}$. This is an open access article under the CC BY license (http://creativecommons.org/licenses/by/4.0/). Received October 05, 2020. Accepted February 07, 2021.
} 
their mRNA (Al-Khalaf and Aboussekhra, 2019). Heterogeneous nuclear ribonucleoprotein $\mathrm{D}$ may be a key regulator of genes associated with hypoxia and mammary gland development.

Although much is known about hypoxia-induced effects on glucose transporters and angiogenesis, an emerging body of research suggests that hypoxia itself is an inflammatory stimulus. Nuclear factor kappa-light-chain-enhancer of activated B cells $(\mathbf{N F}-\mathbf{\kappa} \mathbf{B})$ is a transcription factor that can be activated by hypoxia (Cummins and Taylor, 2005; Cummins et al., 2006; BelAiba et al., 2007; Rius et al., 2008), and HIF1A expression is regulated by NF-kB (van Uden et al., 2008). Nuclear factor- $\kappa B$ controls the expression of inflammatory mediators in addition to playing a critical role in cell proliferation, including mammary gland development (Cao and Karin, 2003). Elevated levels of inflammatory mediators are commonly observed in periparturient dairy cows (Bradford et al., 2015). However, excessive inflammation in early lactation has negative long-term effects on milk production (Bertoni et al., 2008). Administration of sodium salicylate (SS), a nonsteroidal anti-inflammatory drug (NSAID) that inhibits NF- $\kappa$ B activation (Kopp and Ghosh, 1994), for $7 \mathrm{~d}$ following parturition increased whole-lactation milk yield for cows in third or greater lactation but tended to decrease milk yield for first-parity cows (Farney et al., 2013b). During the beginning of a cow's first lactation, hypoxiainduced NF- $\kappa$ B activation is likely an important mechanism to promote mammary gland development. Thus, NSAID administration during a time of intense mammary gland development may explain the parity interaction noted in our previous study. Moreover, we recently found that SS administration increased mammary global DNA methylation (Ylioja et al., 2018), another hint that SS could alter hypoxia-induced effects. Therefore, the objective of the present study was to investigate the effect of SS on hypoxia-induced responses in MAC-T cells. We hypothesized that SS would inhibit the activation of HIF-1 $\alpha$, resulting in decreased transcription of downstream targets responsible for glucose transport (GLUT1) and angiogenesis (VEGFA) due to a reduction in mRNA abundance of $H N R N P D$, a gene involved in altering global DNA methylation patterns.

Immortalized bovine mammary epithelial (MAC-T) cells were kindly donated by Wendi Cohick from Rutgers University (Brunswick, NJ). Dulbecco's modified Eagle's medium (1×; ref no. 11965-092, Life Technologies) containing 10\% fetal bovine serum (cat. no. A3160401, Thermo Fisher Scientific), 100 U/mL penicillin streptomycin (cat. no. 15070, Life Technologies), and 5 $\mu \mathrm{g} / \mathrm{mL}$ insulin (cat. no. 19278; Sigma Aldrich) was used for growing cells and in all experiments. Cells were cultured at $37^{\circ} \mathrm{C}$ with $5 \%$ atmospheric $\mathrm{CO}_{2}$ in humidified incubators. Cell were passed at $80 \%$ confluency. Cells were first washed with $\mathrm{Ca}-$ and $\mathrm{Mg}$-free PBS, and then TrypLE solution (cat. no. 12604013, Thermo Fisher Scientific) was added and cells were incubated for 2 to $5 \mathrm{~min}$ until cells were completely detached. Detached cells were resuspended in fresh medium, quantified with a Neubauer chamber, and plated at the desired cell density.

For experiments, MAC-T cells $\left(10^{6}\right.$ cells/well $)$ were seeded into 12-well cell culture plates. Before treatments were applied, all cells were cultured for $24 \mathrm{~h}$ to reach at least $80 \%$ confluence. Afterward, cells were transfected with either HIF1A small interfering RNA (siRNA) or a scrambled siRNA negative control $48 \mathrm{~h}$ before treatment application. Cell were transfected in serum- and antibiotic- free Opti-MEM medium (cat. no. 11058021, Thermo Fisher Scientific) with a final concentration of $100 \mathrm{n} M$ scrambled negative control (NEG) siRNA (Mission siRNA Universal Negative Control \#1, cat. no. SIC001, Sigma Aldrich), HIF1A siRNA-1, or HIF1A siRNA-2 (Sigma-Aldrich) using Mirus TransIT-X2 Transfection Reagent (cat. no. MIR6000, MirusBio) according to the manufacturer's recommendations. Additionally, some wells underwent this process but without any siRNA duplex (CON). The siRNA duplex sequences were GGAUGAUGACUUCCAGUUAdTdT, UAACUGGAAGUCAUCAUCCdTdT for HIF1A siRNA-1 and CUGAUUUAGACUUGGAGAUdTdT, AUCUCCAAGUCUAAAUCAGdTdT for HIF $1 A$ siRNA-2.

After 48 h, cells were washed with PBS before fresh culture medium containing SS (100 $\mu M$; cat. no. S3007, Sigma-Aldrich) or not was added just before incubation. This dose was based on the approximate mean plasma concentration of salicylate in postpartum cows treated with oral SS (unpublished data from Montgomery et al., 2019). A gas-tight modular incubator chamber (MIC101, Billups-Rothenberg) was flushed for 3 min with $5 \% \mathrm{CO}_{2}$ balanced with $95 \%$ nitrogen, resulting in an oxygen concentration of approximately $1 \%$. Treated cells were immediately placed in this chamber to induce hypoxia $\left(1 \% \mathrm{O}_{2}\right)$ or were placed outside the chamber in normoxic conditions in the incubator $\left(5 \% \mathrm{CO}_{2}\right)$, as in previous studies (Joshi et al., 2011; Portou et al., 2020). Cells were then incubated under either hypoxic or normoxic conditions for 12 $\mathrm{h}$ ( $\mathrm{n}=6-7$ wells per treatment combination).

After the 12-h incubation, the medium was removed and cells were washed with cold PBS. Cells were harvested with $0.5 \mathrm{~mL}$ of Trizol containing $\beta$-mercaptoethanol (1.14 $\mu \mathrm{L} / 0.5 \mathrm{~mL}$ of Trizol), removed using a cell scraper, and stored at $-20^{\circ} \mathrm{C}$ until RNA was harvested. The RNA was extracted (RNeasy Lipid Tissue Mini Kit, Qiagen) according to manufacturer specifications. Concentration and purity of RNA were assessed using spectrophotometry (Take3 Micro-Volume plate, Biotek). Total RNA (mean: $45 \mathrm{ng}$ ) was used to synthesize cDNA in a $20-\mu \mathrm{L}$ reaction using a High-Capacity cDNA Reverse Transcription Kit (Applied Biosystems). Quantitative real-time PCR was performed in duplicate with $1 \mu \mathrm{L}$ of the cDNA product in the presence of $200 \mathrm{nmol} / \mathrm{L}$ gene-specific forward and reverse primers using SYBR Green fluorescent detection (7500 Fast Real-Time PCR System, Applied Biosystems). Primers were designed using the Primer-BLAST tool on the National Center for Biotechnology Information website (https://www.ncbi.nlm .nih.gov/tools/primer-blast/; Table 1). Efficiencies of PCR were determined using a 5-point dilution curve and ranged between 92 and $110 \%$ for all gene targets (Table 1), and transcript abundance was quantified using the relative expression ratio incorporating efficiency from Pfaffl (2001). Numerous housekeeping genes were checked for stability across treatments. Potential internal control gene transcripts RPS9, RPS15, UXT, and neudesin neurotrophic factor $(N E N F)$ were evaluated for stability across treatments; $N E N F$ was selected as the most appropriate internal control because it was readily detectible in all samples, was not altered by treatment $(P=0.67)$, and showed greater stability across samples than the geometric mean of 3 reference genes (Pfaffl et al., 2004). Specificity of primer amplification was verified by melt curve analysis following PCR.

MAC-T cells $\left(10^{6}\right.$ cells/well) were seeded into a 96-well cell culture plate and were treated with SS $(100 \mu M)$ or control medium 
Table 1. Primers used for quantitative PCR analysis

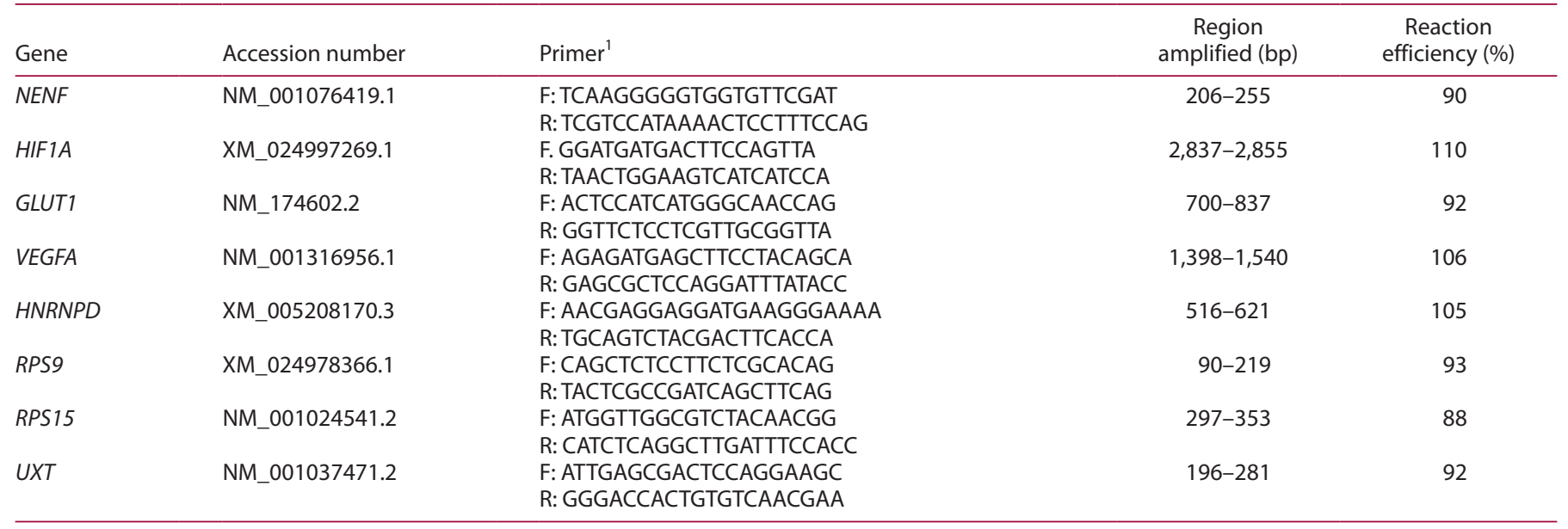

${ }^{1} \mathrm{~F}=$ forward; $\mathrm{R}=$ reverse.

just before incubation under either hypoxic $\left(1 \% \mathrm{O}_{2}\right)$ or normoxic conditions for $12 \mathrm{~h}(\mathrm{n}=6$ per treatment combination). AlamarBlue was incubated with MAC-T cells for $4 \mathrm{~h}$, and the conversion of resazurin to resorufin was used as a proxy for cell viability (cat. no. DAL1025, Invitrogen). Absorbance was determined at $570 \mathrm{~nm}$ using a plate reader (Synergy HTX, BioTek Instruments Inc.) and Gen5 software (BioTek Instruments Inc.).

For cell viability, a linear mixed model (PROC GLIMMIX of SAS 9.4, SAS Institute Inc.) was used with hypoxia, SS, and the interaction as fixed effects and the random effect of cell culture plate nested within hypoxia treatment. Transcript abundance of 4 target genes (HIF1A, GLUT1, VEGFA, and HNRNPD) was analyzed using a linear mixed model (PROC GLIMMIX) with the fixed effects of SS, hypoxia, siRNA, and all 2- and 3-way interaction terms and the random effect of cell culture plate nested within hypoxia treatment. To meet the assumption of normality (PROC UNIVARIATE of SAS 9.4), all mRNA abundance data required natural logarithmic transformation. Least squares means and standard errors were back-transformed according to Jørgensen and Pedersen (1998). An outlier was defined if the observation had a studentized residual greater than 3 in absolute value, and therefore was removed from the analysis. When conducting multiple comparisons, treatment means were separated using Tukey's honestly significant difference test. Significance was declared at $P \leq 0.05$ and tendencies were declared at $0.05<P<0.10$.

For cell viability, the effect of SS depended on the oxygen concentration (Figure 1; SS $\times$ hypoxia, $P<0.01$ ). Further investigation into this interaction yielded marginal effects of SS on cell viability, where SS increased cell viability under hypoxic conditions $(P=$ $0.05)$ and decreased cell viability when cells were cultured in normoxia conditions $(P<0.01)$. In untreated cells, hypoxia marginally decreased cell viability compared with normoxia cells $(P=0.02)$;

\section{Cell viability}

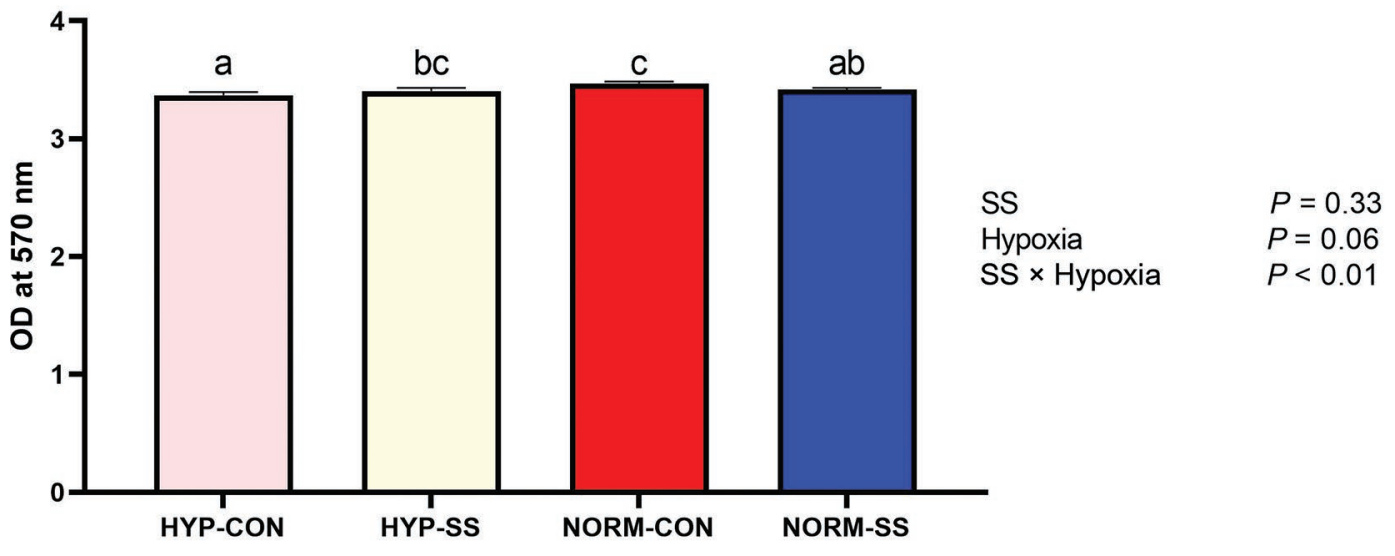

Figure 1. Marginal effects of sodium salicylate (SS) and hypoxia (HYP) on MAC-T cell viability. Sodium salicylate slightly increased cell viability, as measured by resazurin metabolism, under hypoxic conditions $(P=0.05)$ and decreased cell viability when cells were cultured in normoxia (NORM) conditions $(P<0.01)$. In untreated cells, HYP marginally decreased cell viability compared with NORM $(P=0.02)$. Different letters $(\mathrm{a}-\mathrm{c})$ indicate significant differences $(P \leq 0.05)$. CON $=$ control; $\mathrm{OD}=$ optical density. 
however, this cytotoxic effect was not found within the SS-treated cells $(P=0.97)$.

Neither SS nor hypoxia had clear effects on HIF1A (Figure 2A; $P=0.14$ and $P=0.15$, respectively). Statistical contrasts were conducted to evaluate the efficacy of 2 HIF $1 A$ siRNA. Both siRNA-1 and siRNA-2 successfully knocked down HIF1A (CON and NEG vs. siRNA-1 and $-2 ; P<0.01$ ), and both siRNA had similar efficacies (siRNA-1 vs. siRNA-2, $P=0.19$ ). To assess downstream hypoxia-induced transcriptional effects, relative mRNA abundance of GLUT1,VEGFA, and HNRNPD (Figure 2B-D) was quantified. Sodium salicylate interacted with hypoxia to influence transcript abundance of GLUT1 (SS $\times$ hypoxia, $P=0.05$; Figure $2 \mathrm{~B}$ ). Contrasts were conducted to evaluate the effect of SS within oxygen availability as well as the effect of hypoxia within NSAID treatment. Salicylate treatment reduced GLUT1 when MAC-T cells were cultured in normoxia conditions (normoxia SS vs. normoxia
CON, $P<0.01$ ); however, no effect of SS was found when MAC-T cells were cultured in hypoxia conditions (hypoxia SS vs. hypoxia CON, $P=0.39$ ). As expected, hypoxia increased GLUT1 (hypoxia $\mathrm{SS}$ vs. normoxia SS, $P<0.01$; hypoxia $\mathrm{CON}$ vs. normoxia $\mathrm{CON}$, $P=0.01)$; however, no effect of HIF1A siRNA knockdown was found $(P=0.98$; Figure $2 \mathrm{~B})$. No effect of either hypoxia or HIF $1 \mathrm{~A}$ knockdown by siRNA was identified for VEGFA $(P \geq 0.52$; Figure $2 \mathrm{C})$ or HNRNPD $(P \geq 0.52$; Figure $2 \mathrm{D})$. However, SS tended to reduce VEGFA $(P=0.06$; Figure $2 \mathrm{C})$ and decreased HNRNPD $(P$ $=0.03$; Figure $2 \mathrm{D})$ transcript abundance compared with untreated cells.

We hypothesized that SS would reduce mRNA abundance of downstream targets associated with hypoxia through inactivation of HIF-1 $\alpha$. Although salicylate failed to alter HIF1A mRNA, NSAID effects were more apparent in downstream targets as SS decreased GLUT1 in normoxic cells and tended to decrease
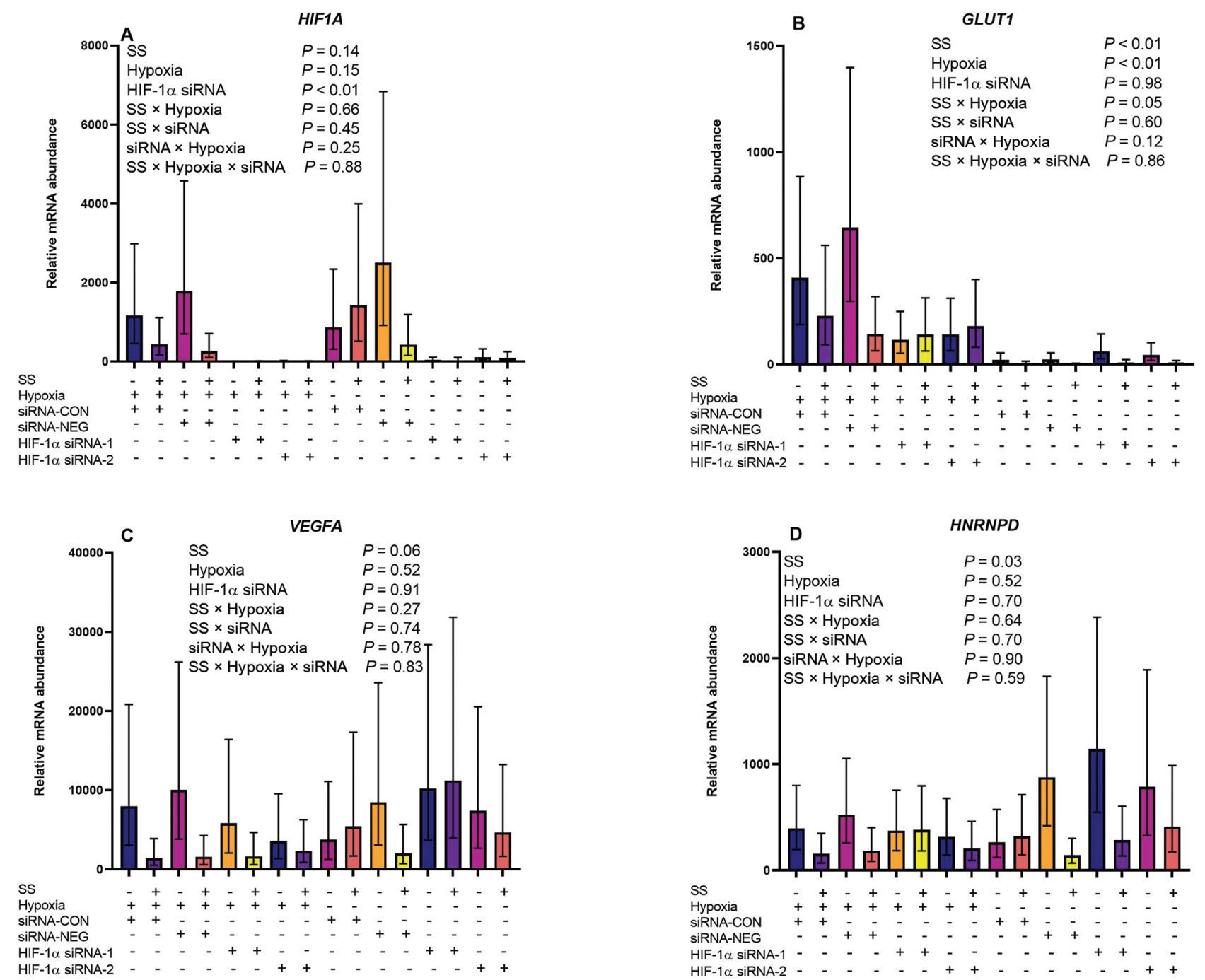

Figure 2. Sodium salicylate (SS) had marginal effects on the transcription factor hypoxia-inducible factor-1 (HIF-1) in MAC-T cells but significantly reduced transcript abundance of downstream targets. Back-transformed LSM $( \pm$ SE) are provided for HIF1A (A), GLUT1 (B), VEGFA (C), and HNRNPD (D) transcript abundance relative to NENF. (A) Small interfering RNA (siRNA)-1 and siRNA-2 successfully knocked down HIF1A (CON and NEG vs. siRNA-1 and siRNA-2, $P<0.01$ ), and both siRNA had similar efficacies (siRNA-1 vs. siRNA-2, $P=0.19$ ). $C O N=$ no siRNA control; NEG = scrambled siRNA negative control. 
VEGFA mRNA regardless of oxygen status. Hypoxia induces inflammation via NF- $\kappa \mathrm{B}$, which in turn activates HIF-1 (HellwigBürgel et al., 1999; van Uden et al., 2008). A reduction in HIF-1a and its downstream targets is likely due to NF- $\kappa B$ sequestration in the cytosol by SS. Numerous studies have demonstrated a protective role for HIF-1 in the gut epithelium (Karhausen et al., 2004; Rosenberger et al., 2009; Clambey et al., 2012), likely to restore tissue homeostasis. These data lead us to speculate that HIF-1 $\alpha$ exerts an anti-inflammatory effect in mammary alveolar cells, and thus the reduction in HIF-1 $\alpha$-related targets by SS treatment likely resulted from a reduced proinflammatory status.

In contrast to our hypothesis, hypoxia did not increase $H I F 1 A$ mRNA abundance in MAC-T cells, although it is important to note that activation of HIF-1 activity in vivo is not necessarily dependent on enhanced HIFlA transcription. We also tested responses to 2 anti-HIF1A siRNA duplexes. Although both siRNA successfully reduced $H I F 1 A$ mRNA abundance, no downstream effects were found on GLUT1, VEGFA, or HNRNPD. The lack of obvious downstream effects may be due to redundant transcription regulation of these genes by numerous transcription factors. For instance, in addition to HIF-1, VEGF (Jośko and Mazurek, 2004) and GLUT1 (Kao and Fong, 2008) are controlled by the transcription factor Sp1.

Salicylate in the present study reduced GLUT1 in normoxia, but no effect of SS was noted in cells cultured under hypoxic conditions. A combination of in vivo and in vitro evidence suggests that GLUT1 is the dominant glucose transporter in bovine mammary epithelial cells (Zhao and Keating, 2007), so suppression of GLUT1 transcription in early-lactation cows would likely constrain glucose availability to support milk lactose synthesis and, to a lesser extent, synthesis of other milk components. However, in our previous studies, oral SS administration reduced blood glucose concentration in multiparous cows due to impaired gluconeogenesis (Montgomery et al., 2019) but had no effect on lactose or milk yield during NSAID treatment (Farney et al., 2013a), which does not align with a central role of mammary GLUT1 in SS responses in vivo.

One potential mechanism behind the downstream transcriptional responses to hypoxia is epigenetics, which is the alteration of gene expression due to chemical modification of DNA or histones. One epigenetic modification is DNA methylation, which controls gene expression by hindering transcription factor binding and consequently repressing transcription (Riggs et al., 1996; Jaenisch and Bird, 2003). As previously mentioned, hypoxia triggers HNRNPD activation, which destabilizes mRNA of the enzyme DNMT1. This enzyme catalyzes the addition of methyl groups to CpG structures in DNA. Thus, a reduction of DNMT1 results in selective DNA hypomethylation, leading to increased expression of hypoxia-associated transcripts (Wu et al., 2019). Salicylate administration in a previous study increased mammary global DNA methylation in multiparous cows (Ylioja et al., 2018), possibly driven by a reduction in HNRNPD. Although we are unsure of how SS reduces HNRNPD transcript abundance, it may be due to its anti-inflammatory and antioxidant properties (Franco et al., 2008). The unraveling of NSAID epigenetic effects in the mammary gland and on dairy cow productivity could be a fruitful area of research (Singh et al., 2010).
We used an in vitro approach here to allow us to narrowly investigate direct interactions between hypoxia and SS without complicating endocrine and other regulatory effects in vivo. Furthermore, we chose to use the MAC-T cell line as a well-characterized model for mammary epithelial cells. However, this cell line does not respond exactly as primary bovine mammary epithelial cells do (Zavizion et al., 1995; Jedrzejczak and Szatkowska, 2014), and possible discrepancies between our findings and the in vivo scenario should be considered.

In conclusion, salicylate reduced mRNA abundance of genes involved with mammary tissue growth and development in MAC$\mathrm{T}$ cells. Future in vivo studies should examine the interactions of NSAID therapy and parity on HIF-1 $\alpha$ abundance and its downstream targets in the mammary gland.

\section{References}

Al-Khalaf, H. H., and A. Aboussekhra. 2019. AUF1 positively controls angiogenesis through mRNA stabilization-dependent up-regulation of HIF-1 $\alpha$ and VEGF-A in human osteosarcoma. Oncotarget 10:4868-4879. https:// doi.org/10.18632/oncotarget.27115.

BelAiba, R. S., S. Bonello, C. Zähringer, S. Schmidt, J. Hess, T. Kietzmann, and A. Görlach. 2007. Hypoxia up-regulates hypoxia-inducible factor-1 $\alpha$ transcription by involving phosphatidylinositol 3-kinase and nuclear factor $\mathrm{\kappa B}$ in pulmonary artery smooth muscle cells. Mol. Biol. Cell 18:4691-4697. https://doi.org/10.1091/mbc.e07-04-0391.

Bertoni, G., E. Trevisi, X. Han, and M. Bionaz. 2008. Effects of inflammatory conditions on liver activity in puerperium period and consequences for performance in dairy cows. J. Dairy Sci. 91:3300-3310. https://doi.org/10 .3168/jds.2008-0995

Bradford, B. J., K. Yuan, J. K. Farney, L. K. Mamedova, and A. J. Carpenter. 2015. Invited review: Inflammation during the transition to lactation: New adventures with an old flame. J. Dairy Sci. 98:6631-6650. https://doi.org/ 10.3168/jds.2015-9683.

Cao, Y., and M. Karin. 2003. NF-kB in mammary gland development and breast cancer. J. Mammary Gland Biol. Neoplasia 8:215-223. https://doi .org/10.1023/A:1025905008934.

Clambey, E. T., E. N. McNamee, J. A. Westrich, L. E. Glover, E. L. Campbell, P. Jedlicka, E. F. de Zoeten, J. C. Cambier, K. R. Stenmark, S. P. Colgan, and H. K. Eltzschig. 2012. Hypoxia-inducible factor-1 alpha-dependent induction of FoxP3 drives regulatory T-cell abundance and function during inflammatory hypoxia of the mucosa. Proc. Natl. Acad. Sci. USA 109:E2784-E2793. https://doi.org/10.1073/pnas.1202366109.

Cummins, E. P., E. Berra, K. M. Comerford, A. Ginouves, K. T. Fitzgerald, F. Seeballuck, C. Godson, J. E. Nielsen, P. Moynagh, J. Pouyssegur, and C. T. Taylor. 2006. Prolyl hydroxylase-1 negatively regulates IкB kinase- $\beta$, giving insight into hypoxia-induced NFאB activity. Proc. Natl. Acad. Sci. USA 103:18154-18159. https://doi.org/10.1073/pnas.0602235103.

Cummins, E. P., and C. T. Taylor. 2005. Hypoxia-responsive transcription factors. Pflugers Arch. 450:363-371. https://doi.org/10.1007/s00424-005 -1413-7.

Davis, A. J., I. R. Fleet, J. A. Goode, M. H. Hamon, F. M. Walker, and M. Peaker. 1979. Changes in mammary function at the onset of lactation in the goat: Correlation with hormonal changes. J. Physiol. 288:33-44.

Farney, J. K., L. K. Mamedova, J. F. Coetzee, B. KuKanich, L. M. Sordillo, S. K. Stoakes, J. E. Minton, L. C. Hollis, and B. J. Bradford. 2013a Anti-inflammatory salicylate treatment alters the metabolic adaptations to lactation in dairy cattle. Am. J. Physiol. Regul. Integr. Comp. Physiol. 305:R110-R117. https://doi.org/10.1152/ajpregu.00152.2013.

Farney, J. K., L. K. Mamedova, J. F. Coetzee, J. E. Minton, L. C. Hollis, and B. J. Bradford. 2013b. Sodium salicylate treatment in early lactation increases whole-lactation milk and milk fat yield in mature dairy cows. J. Dairy Sci. 96:7709-7718. https://doi.org/10.3168/jds.2013-7088.

Finucane, K. A., T. B. McFadden, J. P. Bond, J. J. Kennelly, and F.-Q. Zhao. 2008. Onset of lactation in the bovine mammary gland: Gene expression profiling indicates a strong inhibition of gene expression in cell proliferation. Funct. Integr. Genomics 8:251-264. https://doi.org/10.1007/s10142 $-008-0074-y$. 
Forsythe, J. A., B.-H. Jiang, N. V. Iyer, F. Agani, S. W. Leung, R. D. Koos, and G. L. Semenza. 1996. Activation of vascular endothelial growth factor gene transcription by hypoxia-inducible factor 1. Mol. Cell. Biol. 16:4604-4613. https://doi.org/10.1128/MCB.16.9.4604.

Franco, R., O. Schoneveld, A. G. Georgakilas, and M. I. Panayiotidis. 2008. Oxidative stress, DNA methylation and carcinogenesis. Cancer Lett. 266:6-11. https://doi.org/10.1016/j.canlet.2008.02.026.

Hellwig-Bürgel, T., K. Rutkowski, E. Metzen, J. Fandrey, and W. Jelkmann. 1999. Interleukin- $1 \beta$ and tumor necrosis factor- $\alpha$ stimulate DNA binding of hypoxia-inducible factor-1. Blood 94:1561-1567. https://doi.org/10.1182/ blood.V94.5.1561.

Hsiao, K.-Y., M.-H. Wu, N. Chang, S.-H. Yang, C.-W. Wu, H. S. Sun, and S.-J. Tsai. 2015. Coordination of AUF1 and miR-148a destabilizes DNA methyltransferase $1 \mathrm{mRNA}$ under hypoxia in endometriosis. Mol. Hum. Reprod. 21:894-904. https://doi.org/10.1093/molehr/gav054.

Jaenisch, R., and A. Bird. 2003. Epigenetic regulation of gene expression: How the genome integrates intrinsic and environmental signals. J. Nat. Genet. 33(S3):245-254. https://doi.org/10.1038/ng1089.

Jedrzejczak, M., and I. Szatkowska. 2014. Bovine mammary epithelial cell cultures for the study of mammary gland functions. In Vitro Cell Dev. Biol. Anim. 50:389-398. https://doi.org/10.1007/s11626-013-9711-4.

Jørgensen, E., and A. R. Pedersen. 1998. How to obtain those nasty standard errors from transformed data-And why they should not be used. Biometry Research Unit Internal report 7. Danish Institute of Agricultural Sciences.

Joshi, D., H. Patel, D. M. Baker, X. Shiwen, D. J. Abraham, and J. C. Tsui. 2011. Development of an in vitro model of myotube ischemia. Lab. Invest. 91:1241-1252. https://doi.org/10.1038/labinvest.2011.79.

Jośko, J., and M. Mazurek. 2004. Transcription factors having impact on vascular endothelial growth factor (VEGF) gene expression in angiogenesis. Med. Sci. Monit. 10:RA89-RA98.

Kao, Y.-S., and J. C. Fong. 2008. Endothelin-1 induces glut1 transcription through enhanced interaction between $\mathrm{Sp} 1$ and NF- $\mathrm{kB}$ transcription factors. Cell. Signal. 20:771-778. https://doi.org/10.1016/j.cellsig.2007.12 .012 .

Karhausen, J., G. T. Furuta, J. E. Tomaszewski, R. S. Johnson, S. P. Colgan, and V. H. Haase. 2004. Epithelial hypoxia-inducible factor-1 is protective in murine experimental colitis. J. Clin. Invest. 114:1098-1106. https://doi .org/10.1172/JCI200421086.

Komatsu, T., F. Itoh, S. Kushibiki, and K. Hodate. 2005. Changes in gene expression of glucose transporters in lactating and nonlactating cows. J. Anim. Sci. 83:557-564. https://doi.org/10.2527/2005.833557x.

Kopp, E., and S. Ghosh. 1994. Inhibition of NF-kappa B by sodium salicylate and aspirin. Science 265:956-959. https://doi.org/10.1126/science .8052854 .

Mattmiller, S. A., C. M. Corl, J. C. Gandy, J. J. Loor, and L. M. Sordillo. 2011. Glucose transporter and hypoxia-associated gene expression in the mammary gland of transition dairy cattle. J. Dairy Sci. 94:2912-2922. https:// doi.org/10.3168/jds.2010-3936.

Montgomery, S. R., L. K. Mamedova, M. Zachut, G. Kra, S. Häussler, M. Vaughn, J. Gonzalez, and B. J. Bradford. 2019. Effects of sodium salicylate on glucose kinetics and insulin signaling in postpartum dairy cows. J. Dairy Sci. 102:1617-1629. https://doi.org/10.3168/jds.2018-15312.

Pfaffl, M. W. 2001. A new mathematical model for relative quantification in real-time RT-PCR. Nucleic Acids Res. 29:e45. https://doi.org/10.1093/nar/ 29.9.e45.

Pfaffl, M. W., A. Tichopad, C. Prgomet, and T. P. Neuvians. 2004. Determination of stable housekeeping genes, differentially regulated target genes and sample integrity: BestKeeper-Excel-based tool using pair-wise correlations. Biotechnol. Lett. 26:509-515. https://doi.org/10.1023/B:BILE .0000019559 .84305 .47 .

Portou, M. J., R. Yu, D. Baker, S. Xu, D. Abraham, and J. Tsui. 2020. Hyperglycaemia and ischaemia impair wound healing via toll-like receptor 4 pathway activation in vitro and in an experimental murine model. Eur. J. Vasc. Endovasc. Surg. 59:117-127.

Reynolds, M. 1967. Mammary respiration in lactating goats. Am. J. Physiol. 212:707-710. https://doi.org/10.1152/ajplegacy.1967.212.3.707.

Riggs, A. D., V. E. A. Russo, and R. A. Martienssen. 1996. Epigenetic Mechanisms of Gene Regulation. Cold Spring Harbor Laboratory Press.
Rius, J., M. Guma, C. Schachtrup, K. Akassoglou, A. S. Zinkernagel, V. Nizet, R. S. Johnson, G. G. Haddad, and M. Karin. 2008. NF-kB links innate immunity to the hypoxic response through transcriptional regulation of HIF-1 $\alpha$. Nature 453:807-811. https://doi.org/10.1038/nature06905.

Rosenberger, P., J. M. Schwab, V. Mirakaj, E. Masekowsky, A. Mager, J. C. Morote-Garcia, K. Unertl, and H. K. Eltzschig. 2009. Hypoxia-inducible factor-dependent induction of netrin-1 dampens inflammation caused by hypoxia. Nat. Immunol. 10:195-202. https://doi.org/10.1038/ni.1683.

Seagroves, T. N., D. Hadsell, J. McManaman, C. Palmer, D. Liao, W. McNulty, B. Welm, K.-U. Wagner, M. Neville, and R. S. Johnson. 2003. HIF $1 \alpha$ is a critical regulator of secretory differentiation and activation, but not vascular expansion, in the mouse mammary gland. Development 130:1713-1724. https://doi.org/10.1242/dev.00403.

Semenza, G. L. 2003. Targeting HIF-1 for cancer therapy. Nat. Rev. Cancer 3:721-732. https://doi.org/10.1038/nrc1187.

Shao, Y., T. L. Wellman, K. M. Lounsbury, and F.-Q. Zhao. 2014. Differential regulation of GLUT1 and GLUT8 expression by hypoxia in mammary epithelial cells. Am. J. Physiol. Regul. Integr. Comp. Physiol. 307:R237R247. https://doi.org/10.1152/ajpregu.00093.2014.

Shao, Y., and F.-Q. Zhao. 2014. Emerging evidence of the physiological role of hypoxia in mammary development and lactation. J. Anim. Sci. Biotechnol. 5:9. https://doi.org/10.1186/2049-1891-5-9.

Singh, K., R. A. Erdman, K. M. Swanson, A. J. Molenaar, N. J. Maqbool, T. T. Wheeler, J. A. Arias, E. C. Quinn-Walsh, and K. Stelwagen. 2010. Epigenetic regulation of milk production in dairy cows. J. Mammary Gland Biol Neoplasia 15:101-112. https://doi.org/10.1007/s10911-010-9164-2.

Torrisani, J., A. Unterberger, S. R. Tendulkar, K. Shikimi, and M. Szyf. 2007. AUF1 cell cycle variations define genomic DNA methylation by regulation of DNMT1 mRNA stability. Mol. Cell. Biol. 27:395-410.

Tucker, H. A. 2000. Hormones, mammary growth, and lactation: A 41-year perspective. J. Dairy Sci. 83:874-884. https://doi.org/10.3168/jds.S0022 $-0302(00) 74951-4$.

van Uden, P., N. S. Kenneth, and S. Rocha. 2008. Regulation of hypoxiainducible factor- $1 \alpha$ by NF- $\kappa$ B. Biochem. J. 412:477-484. https://doi.org/ 10.1042/BJ20080476.

Wu, M.-H., K.-Y. Hsiao, and S.-J. Tsai. 2019. Hypoxia: The force of endometriosis. J. Obstet. Gynaecol. Res. 45:532-541. https://doi.org/10.1111/jog .13900 .

Ylioja, C. M., A. J. Carpenter, M. Garcia, L. K. Mamedova, and B. J. Bradford. 2018. Anti-inflammatory treatment in early lactation alters global mammary DNA methylation. J. Dairy Sci. 101(Suppl. 2):274. (Abstr.)

Zavizion, B., R. C. Gorewit, and I. Politis. 1995. Subcloning the MAC-T bovine mammary epithelial cell line: Morphology, growth properties, and cytogenetic analysis of clonal cells. J. Dairy Sci. 78:515-527. https://doi .org/10.3168/jds.S0022-0302(95)76662-0.

Zhao, F.-Q. 2014. Biology of glucose transport in the mammary gland. J. Mammary Gland Biol. Neoplasia 19:3-17. https://doi.org/10.1007/s10911-013 $-9310-8$.

Zhao, F.-Q., and A. F. Keating. 2007. Expression and regulation of glucose transporters in the bovine mammary gland. J. Dairy Sci. 90(Suppl. 1):E76E86.

\section{Notes}

C. M. Ylioja ๑ https://orcid.org/0000-0003-1564-9534

T. H. Swartz @ https://orcid.org/0000-0002-9457-2418

L. K. Mamedova $\odot$ https://orcid.org/0000-0003-3612-0381

B. J. Bradford ๑ https://orcid.org/0000-0002-6775-4961

This project was supported by the USDA Agriculture and Food Research Initiative, National Institute of Food and Agriculture (AFRI-NIFA, Washington, DC) Fellows Program, grant no. 2017-67011-26044, as well as by AFRI-NIFA Hatch Project 1018048.

The graphical abstract was created using BioRender (biorender.com).

The authors have not stated any conflicts of interest. 